\title{
Chemical Composition and Pulping of Tunisian Almond and Fig Stems - A Comparison with Tunisian Date Palm Rachis
}

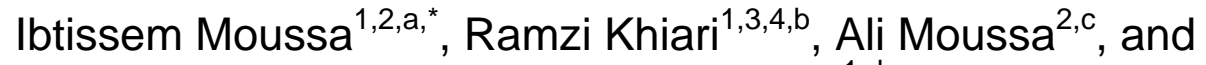 \\ Mohamed Farouk Mhenni ${ }^{1, d}$ \\ ${ }^{1}$ Research Unity of Applied Chemistry \& Environment, Faculty of Sciences, The university of \\ Monastir, Tunisia \\ ${ }^{2}$ National Engineering School of Monastir, The university of Monastir, Tunisia. \\ ${ }^{3}$ CNRS, LGP2, The university of Grenoble Alpes, France \\ ${ }^{4}$ Department of Textile, Higher Institute of Technological Studies of Ksar Hellal, The university \\ of Monastir, Tunisia \\ amoussa.ibtissem@hotmail.fr, ${ }^{b}$ khiari_ramzi2000@yahoo.fr, cali.moussa76@yahoo.fr, \\ dfarouk.mhenni@gmail.com
}

Keywords: date palm rachis, almond stems, fig stems, cellulose fiber, characterization

\begin{abstract}
In the present paper, the main objectives of this paper are the characterization of two Tunisian cellulosic by-products (almond and fig stems). The first part of this work is devoted to the determination of the chemical composition. Their chemical composition was showed that they present amounts of holocellulose, lignin and cellulose similar to those encountered in Tunisian date palm rachis. In the second part of this paper, the ensuing pulps of almond and fig stems are characterized in terms of degree of polymerization, fiber length and fiber width. These properties were compared to the properties of a Tunisian date palm rachis that was fully characterized by Khiari et al. (2010). Finally, the results of this work clearly demonstrated that almond and fig stems can be considered as a possible alternative source of fibers for cellulose derivatives and/or as lignocellulosic fibers for fiber-reinforced composite materials or papermaking application.
\end{abstract}

\section{Introduction}

The increase in fibers demand will be met by increased forestry production, which will give growth to global deforestation, with unsafe results to the environment. However, owing to the increasing fiber concerns and the potential increases in wood expenses, non-wood materials like annual plants have received more attention to produce pulp and/or paper and/or cellulose derivatives and/or composites. Lignocellulosic wastes are used as animal feed or burn in the soil or left to decompose. The utilization of these cheap and widely disposable wastes does not resolve just the environment pollution but also makes additional value.

Pulping methods have been modified these days by addition of certain chemicals, e.g. anthraquinone, to the basic pulping chemicals (soda and kraft) [1-4]. The choice of pulping chemicals is informed by literature indicating that addition of anthraquinone to soda pulping would have better advantages [5,6]. Adding anthraquinone as catalyst in sodium hydroxide system increases the pulp yields, decreases the kappa numbers, and improves the strength properties. It also increases lignin removal by promoting cleavage of inter-unit bonds in the lignin molecules that are not cleaved in the absence of anthraquinone. It also helps minimize recondensation of lignin reactions by reacting with the carbohydrates to increase lignin removal during pulping process and produced cellulose with high yield. 
The valorization of isolated fibers from Tunisian date palm rachis have been investigated by Khiari et al. (2010) for the making of paper, green composites and cellulose derivatives [7-9]. Date palm waste is widely available agricultural crops in Tunisia, which has more than four million dates palm trees occupying 33 thousand hectares. In our paper, two lignocellulosic materials were studied, largely disposable in Tunisia, as a source of cellulosic fibers, namely: almond and fig stems.

According to the Food and Agricultural Organization (FAO), Tunisia is ranked as the $8^{\text {th }}$ producing country of almond with about 3.8\% of the total world production [10]. The main production space is located in coastal areas (Bizerte, Cap Bon, Mahdia, Sfax, Zarzis, Djerba, Kerkenah, etc.) and in some mountainous regions (Gafsa, Beni Khedache, etc.). Fig (Ficus carica L.) is amongst the coventional Mediterranean species. Figs have recently attracted a great deal of attention and therefore are widespread across the world. The entire world produces over 1000 000 tons of figs yearly, of which $82 \%$ are manufactured in Mediterranean countries [11]. In Tunisia, the production is all about 29000 tons; it represents $3 \%$ of overall international production [11]. Almond and fig stems are by-products which have no proven uses. They are incinerated or dumped. This paper aims at deep understanding of the chemical and structural composition of these wastes and its cellulosic fibers. These properties were compared to the properties of a Tunisian date palm rachis that was fully characterized by Khiari et al. (2010).

\section{Materials and Methods \\ Materials}

The almond (Prunus amygdalus L.) and fig (Ficus carica L.) (Fig. 1) used during this work were cultivated in Monastir (city on the central coast of Tunisia).

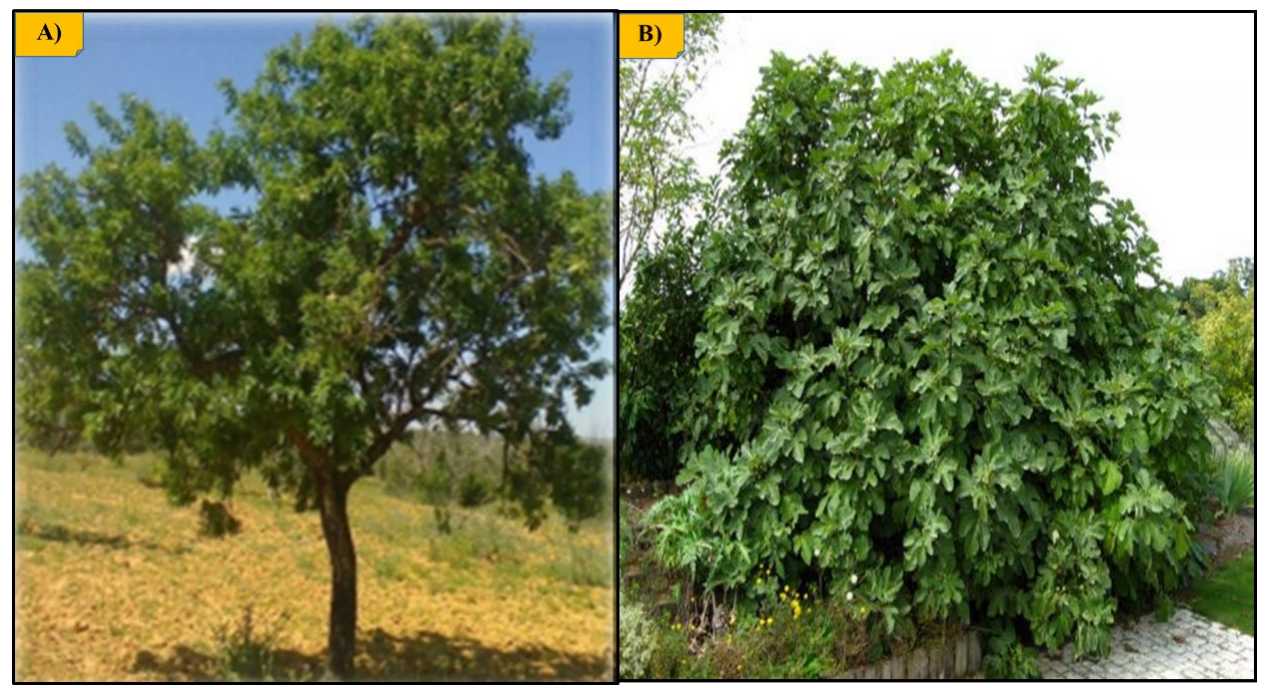

Fig. 1. A) Almond tree (Prunus amygdalus L.) and B) Fig tree (Ficus carica L.).

\section{Chemical Composition}

The chemical composition of the raw materials studied here was established. Thus, the contents of Klason lignin, holocellulose, as well as $\alpha$-cellulose were assessed by using different standards or methods, as summarized in Table $2[1,4]$. The amounts of lignin and $\alpha$-cellulose were established by using the following respective TAPPI methods: T222 om-02; T203 cm-99. Finally, the holocellulose content was determined according to the method described by Wise (1946) [12]. The ashes content was determined, according to the standard procedure TAPPI $\mathrm{T} 211 \mathrm{om}-02$, by calcinations of the materials at $525 \pm 25^{\circ} \mathrm{C}$ for at least 4 hours. 
The evaluation of extractives was carried out in different liquids according to common standards, namely, cold and hot water solubility (T207 cm-99), 1\% sodium hydroxide solution solubility (T212 om-02), and ethanol-toluene solubility (T204 cm-97).

Ethanol-toluene extractives: This method describes a procedure for determining the amount of solvent-soluble, non-volatile material in wood and pulp.

Cold and hot water extractives: The cold-water procedure removes a part of extraneous components, such as inorganic compounds, tannins, gums, sugars, and coloring matter present in wood and pulp. The hot-water procedure removes, in addition, starches.

1\% sodium hydroxide solution extractives: Hot alkali solution extracts low-molecular-weight carbohydrates consisting mainly of hemicellulose and degraded cellulose in our agricultural wastes. The solubility could indicate the degree of a fungus decay or of degradation by heat, light, oxidation, etc. As agricultural waste decays or degrades, the percentage of the alkalisoluble material increases. The solubility of our agricultural wastes indicates also an extent of cellulose degradation during pulping and bleaching processes.

\section{Ion Chromatography}

The ion chromatography is an analytical technique which able to separate and quantify quantitatively only five monosaccharides (Glucose, Xylose, Galactose, Arabinose and Mannose). It is a method which gave the best recovery of sugars with minimum hydrolysis of sucrose.

The analytical hydrolysis procedure uses a two-step acid hydrolysis [13]. Primary hydrolysis of $350 \mathrm{mg}$ sample was performed with $3 \mathrm{~mL} 72 \%$ (w/w) $\mathrm{H}_{2} \mathrm{SO}_{4}$ for an hour at $30^{\circ} \mathrm{C}$. Hydrolysates were diluted to $4 \%(\mathrm{w} / \mathrm{w}) \mathrm{H}_{2} \mathrm{SO}_{4}$ with distilled water. A secondary hydrolysis performed for 60 minutes at $120^{\circ} \mathrm{C}$ in autoclave ( 1 bar) to fractionate the biomass into forms which are more easily quantified. Fucose was added as an internal standard. The hydrolysates were diluted with $\mathrm{H}_{2} \mathrm{O}$. Following filtration, $10 \mu \mathrm{L}$ samples of hydrolysates were injected directly onto the chromatographic system without any additional treatment.

Sugar contents of hydrolysates were determined by CI. The chromatographic system consisted of a 738-autosampler (Alcott Chromatography, Norcross, GA), a GPM-1 or a GP40 gradient high-pressure pump (Dionex Corp., Sunnyvale, CA), and a pulsed amperometric detector (PAD) (Dionex).

\section{Extraction of Cellulose}

The extraction of cellulose was prepared based on our previous studies [1,4]. The preparation of extracted bleached cellulose was conducted in two steps: pulping and bleaching. In our case, the operation of delignification (pulping) consisted of extracting and isolating the cellulosic fibers by adopting a chemical soda-anthraquinone process. The delignification stage of the almond and fig stems were performed according to experimental conditions described in a previous publication $[1,4]$. The obtained pulp was separated from black liquor and washed several times, until a neutral $\mathrm{pH}$ was attained. The bleaching step was performed according to experimental conditions described in a previous publication [1,4] using $100 \mathrm{~mL}$ of sodium hypochlorite solution (30\%, $\mathrm{v} / \mathrm{v}$ ) (12\% of active chlorine) in an alkaline basic medium $\mathrm{pH}$ (pH varied between 9 and 11) for $180 \mathrm{~min}$ at $45^{\circ} \mathrm{C}$. Finally, the bleached fibers were extensively washed with water until their $\mathrm{pH}$ was neutral, then purified by an anti-chlorine treatment and air dried before further use.

\section{Morfi}

Morphological properties of the fibres were studied by a morfi (LB-01) analyzer developed by Techpap - France [14]. The main fiber parameters were assessed by image analysis of a diluted 
suspension flowing in a transparent flat channel observed by a CCD video-camera. The average weighted length and the average width were measured and evaluated.

\section{Carbanilation Reaction of Cellulose}

Cellulose (15 mg) was place in test tube equipped with micro stir bars and dried overnight under vacuum at $40^{\circ} \mathrm{C}$. Following the addition of anhydrous pyridine $(4 \mathrm{~mL})$ and phenyl isocyanate $(0.5 \mathrm{~mL})$, the test tube was permitted to stir for 48 hours at $70^{\circ} \mathrm{C}$. Then, methanol $(1 \mathrm{~mL})$ was added to quench the phenyl isocyanate. Next, the contents of test tube was put into 7:3 (v:v) methanol:water $(100 \mathrm{~mL})$ to precipitate the derivatized cellulose. Finally, the solid was filtrated, washed with the methanol: water solution followed by deionized water and dried overnight under vacuum at $40^{\circ} \mathrm{C}$.

\section{Molecular weight distribution of cellulose}

The derivatized cellulose was dissolved in tetrahydrofuran (THF) (1 mg.mL $\left.{ }^{-1}\right)$, filtered through a $0.45 \mathrm{~mm}$ filter and placed in a $2 \mathrm{~mL}$ auto-sampler vial. The molecular weight distributions of the cellulose tricarbanilate samples were analyzed on an Agilent GPC security 1200 system. Molecular weight was calculated by the software relative to the polystyrene calibration curve. Weight average degree of polymerization $\left(\mathrm{DP}_{\mathrm{w}}\right)$ was obtained by dividing $\mathrm{M}_{\mathrm{w}}$ by the molecular weight of the tri-carbanilated cellulose repeat unit $\left(519\right.$ g.mol $\left.{ }^{-1}\right)$.

\section{Results and Discussion \\ Chemical Composition}

The ash contents of almond and fig stems were rather high (3-5\%) as indicated in (Table 1), but typical for tropical non-woody plants. The hot water extractives from fig and almond stems were (12.7 and 16.7\%), cold water (9 and 12\%), ethanol-toluene extractives (4 and 7\%), and 1\% $\mathrm{NaOH}$ (21 and 29\%) were rather high due to the presence of many soluble polysaccharides and phenolic compounds.

On the other hand they are an indication of easy access and degradation of the cell wall materials by weak alkali. The cellulose content of fig stems was $47 \%$ which meant good pulp yields at suitable alkali utilization. The lignin content of fig stems was $19 \%$ which was relatively moderate. This should result in moderate cooking chemical charges and a short cooking cycle. Cellulose to lignin ratio was higher than 2 and predicted normal pulping with alkaline methods. High cellulose content and low content of lignin as well as organic and inorganic substances indicate the suitability of biomass for the production of cellulose fibres.

In paper production the primary role of hemicelluloses is to imbibe water and thus to contribute to fiber swelling. This leads to internal lubrication of the fiber and improves its flexibility and ease of beating. The swelling pressure contributes to loosening of the structure and fibrillation. The hemicelluloses being amorphous and adhesive in nature tend to hornify as the fiber shrinks and dries. Thus hemicelluloses serve as a matrix binding substance between fibers in a pulp.

The chemical composition of date palm rachis is summarized in Table 1, which shows that the amounts of extractives in water (cold, hot) are in the range of 5-8\%, which is slightly lower when compared with almond and fig stems. Whereas ethanol-toluene extractives, $1 \% \mathrm{NaOH}$ extractives, and ashes are comparable to those of our annual agricultural crops, holocellulose was found to be relatively high (around 74\%).

The Tunisian almond and fig stems wastes are characterized by large amounts of cellulose. The cellulose content of fig stems (47\%) was higher than date palm rachis. 
The Klason lignin of date palm rachis is in the range of $27 \%$, which is higher than fig stems and lower than almond stems. Moreover, rachis has slightly lower lignin content than other woody biomass like eucalyptus (29-32\%) and pine (28\%) [15].

Table 1. Characterization of almond and fig stems

\begin{tabular}{llll} 
Components & Fig stems & Almond stems & Date palm rachis [8] \\
\hline Cold water extractives (\%) & 9.24 & 12.17 & 5 \\
Hot water extractives (\%) & 12.70 & 16.70 & 8.1 \\
Ethanol-toluene extractives (\%) & 4.18 & 7.02 & 6.3 \\
1\% NaOH extractives (\%) & 21.57 & 29.01 & 20.8 \\
Ash (\%) & 5.10 & 3.39 & 5 \\
Klason lignin (\%) & 19.64 & 34.35 & 27.2 \\
Holocellulose (\%) & 60.11 & 50.66 & 74.8 \\
Cellulose (\%) & 47.06 & 31.41 & 45 \\
\hline
\end{tabular}

Their carbohydrate composition, are given in Table 2. As seen, there was significant difference in the carbohydrate composition. Almond and fig stems consisted mainly of glucan, xylan and galactan. Glucomannan and mannan were present in relatively minor quantities. Glucose and xylose are the main components of fig and almond stems, while galactose and arabinose were present in relatively minor quantities.

Table 2. Carbohydrate composition ( $\mathrm{mg} / \mathrm{g}$ dry weight) of almond and fig stems

\begin{tabular}{lll}
\hline & Almond stems & Fig stems \\
\hline Glucan & 342.777 & 511.458 \\
Xylan & 94.458 & 96.036 \\
Galactan & 60.631 & 26.333 \\
Mannan & 0.000 & 10.519 \\
Glucomannan & 0.153 & 0.107 \\
\hline
\end{tabular}

Glucan and xylan contents were 20.62 and $10.53 \%$ (based on dry matter) in leaflets, while they were 38.34 and $20.07 \%$ in rachis [16]. Carbohydrate contents (glucan and xylan) of rachis are comparably high with conventional lignocellulosic biomass around the world like corn stover (30-38\% and 20-25\%), wheat straw (34-40\% and 21-26\%), and sugarcane bagasse (32-43\% and 22-25\%) [17].

Given the high carbohydrates and low lignin content, date palm rachis seems to be a potential source of woody biomass for biorefnery or it can be considered as a possible alternative source of fibers for cellulose derivatives and/or as lignocellulosic fibers for fiber-reinforced composite materials or papermaking application. Conversely, leaflets have signifcantly lower carbohydrates content and higher lignin content than conventional lignocellulosic biomass, making date palm leaflets a potential biomass candidate for lignin production.

\section{Morphological Investigation}

As shown in Table 3, based on morfi analyse, it can be noticed that fibers extracted from almond and fig stems present the same length, but the diameter of the fiber of almond stems is lower than the fig stems. The degree of polymerization (DP) of fibers extracted from almond and fig stems were determined by using gel permeation chromatography (GPC) technique. The relation in DP and the strength of fibers is rather obvious i.e. higher the DP higher the tensile strength [18-21]. 
The DP of the fiber extracted from date palm rachis is lower than fibers extracted from almond and fig stems.

The principal factors controlling the strength of paper are fibre length and strength [22]. The fibers from the two stems studied (almond and fig stems) were in the range of hardwood fibers, with short fiber length, as shown in Table 3, with more or less moderate walls and fiber width. The fibres from the date palm rachis were also in the range of hardwood fibres with short fibre length $(0.89 \mathrm{~mm})$ and width $(22.3 \mu \mathrm{m})$.

Table 3. Morpholigical of fibers

\begin{tabular}{lccccccc} 
& $\begin{array}{c}M_{n} \\
\text { (Daltons) }\end{array}$ & $D P_{n}$ & $\begin{array}{c}M_{w} \\
\text { (Daltons) }\end{array}$ & $D P_{w}$ & $M_{w} / M_{n}$ & $\begin{array}{c}\text { Fiber } \\
\text { length } \\
(\mathrm{mm})\end{array}$ & $\begin{array}{c}\text { Fiber } \\
\text { width } \\
(\mu \mathrm{m})\end{array}$ \\
\hline Almond stems & 643436 & 1021 & 958721 & 1521 & 1.49 & 0.518 & 19.6 \\
\hline Fig stems & 589934 & 1113 & 985190 & 1563 & 1.67 & 0.516 & 22.4 \\
\hline Date palm rachis [8] & - & - & - & 1203 & - & 0.890 & 22.3 \\
\hline
\end{tabular}

\section{Conclusion}

The chemical composition of almond and fig stems was showed that they present amounts of holocellulose, lignin and cellulose similar to those encountered in date palm rachis. Given the high carbohydrates and low lignin content, almond stems especially the fig stems seem to be potential sources of woody biomass for biorefnery or they can be considered as alternative sources of fibers for cellulose derivatives or fiber-reinforced composite materials or papermaking application. The performance of the fiber extracted from almond stems is better than fibers extracted from fig stems and date palm rachis.

\section{References}

[1] I. Moussa, R. Khiari, A. Moussa, R.E. Abouzeid, M.F. Mhenni, F. Malek, Variation of Chemical and Morphological Properties of Different Parts of Prunus Amygdalus L and Their Effects on Pulping, Egypt. J. Chem. 62 (2019) 343-356.

https://doi.org/10.21608/ejchem.2018.4827.1429

[2] Z. Marrakchi, R. Khiari, H. Oueslati, E. Mauret, F. Mhenni, Pulping and papermaking properties of Tunisian Alfa stems (Stipa tenacissima)—Effects of refining process, Ind. Crops Prod. 34 (2011) 1572-1582. https://doi.org/10.1016/j.indcrop.2011.05.022

[3] A. El Gendy, R. Khiari, F. Bettaieb, N. Marlin, A. Dufresne, Preparation and application of chemically modified kaolin as fillers in Egyptian kraft bagasse pulp, Appl. Clay Sci. 101 (2014) 626-631. https://doi.org/10.1016/j.clay.2014.09.032

[4] I. Moussa, R. Khiari, A. Moussa, M.F. Mhenni, M. Naceur Belgacem, Physico-chemical characterization of polysaccharides and extraction of cellulose from annual agricultural wastes, Cellul. Chem. Technol. 52 (2018) 841-851.

[5] P.W. Hart, A.W. Rudie, Anthraquinone - A Review of the Rise and Fall of a Pulping Catalyst, Tappi J. 13 (2014) 23-31.

[6] A. Rodríguez, R. Sánchez, M.E. Eugenio, R. Yáñez, L. Jiménez, Soda-anthraquinone pulping of residues from oil palm industry, Cellul. Chem. Technol. 44 (2010) 239-248. 
[7] K. Ramzi, M. Nizar, M. Farouk, B.M. Naceur, M. Evelyne, Sodium carboxylmethylate cellulose from date palm rachis as a sizing agent for cotton yarn, Fibers Polym. 12 (2011) 587593. https://doi.org/10.1007/s12221-011-0587-1

[8] R. Khiari, M.F. Mhenni, M.N. Belgacem, E. Mauret, Chemical composition and pulping of date palm rachis and Posidonia oceanica - A comparison with other wood and non-wood fibre sources, Bioresour. Technol. 101 (2010) 775-780. https://doi.org/10.1016/j.biortech.2009.08.079 [9] R. Khiari, E. Mauret, M.N. Belgacem, F. Mhenni, Tunisian date palm rachis used as an alternative source of fibres for papermaking applications, Bioresources 6 (2011) 265-281. [10]Z. Hu, M.P. Srinivasan, Y. Ni, Preparation of Mesoporous High-Surface-Area Activated Carbon, Adv. Mater. 12 (2000) 62-65. https://doi.org/10.1002/(sici)15214095(200001)12:1\%3C62::aid-adma62\%3E3.0.co;2-b [11] Information on: http://www.fao.org/faostat/en/\#home. [12] L. Wise, Chlorite holocellulose, its fractionation and bearing on summative wood analysis and on studies on the hemicelluloses, Paper Trade J. 122 (1946) 35-43.

[13]J.F. Saeman, W.E. Moore, R.L. Mitchell, M.A. Millett, Techniques for the determination of pulp constituents by quantitiative paper chromatography, Tappi J. 37 (1954) 336-343.

[14] R. Passas, M. Lecourt, P. Nougier, W. Minko, B. Khelifi, Effets de la remise en suspension des pâtes sur leur caractérisation morphologique, ATIP. Assoc. Tech. 58 (2002) 6-13. [15]A.J. Ragauskas, G.T. Beckham, M.J. Biddy, R. Chandra, F. Chen, M.F. Davis, B.H. Davison, R.A. Dixon, P. Gilna, M. Keller, P. Langan, A.K. Naskar, J.N. Saddler, T.J. Tschaplinski, G.A. Tuskan, C.E. Wyman, Lignin Valorization: Improving Lignin Processing in the Biorefinery, Science 80 (2014) 1246843-1246843. https://doi.org/10.1126/science.1246843 [16]C. Fang, J.E. Schmidt, I. Cybulska, G.P. Brudecki, C.G. Frankær, M.H. Thomsen, Hydrothermal Pretreatment of Date Palm (Phoenix dactylifera L) Leaflets and Rachis to Enhance Enzymatic Digestibility and Bioethanol Potential, Biomed Res. Int. 2015 (2015) 1-13. https://doi.org/10.1155/2015/216454

[17]T.S. Khan, U. Mubeen, Wheat Straw: A Pragmatic Overview, Curr. Res. J. Biol. Sci. 4 (2012) 673-675.

[18] N.R.J. Hyness, N.J. Vignesh, P. Senthamaraikannan, S.S. Saravanakumar, M.R. Sanjay, Characterization of New Natural Cellulosic Fiber from Heteropogon Contortus Plant, J. Nat. Fibers 15 (2018) 146-153. https://doi.org/10.1080/15440478.2017.1321516

[19]S.S. Saravanakumar, A. Kumaravel, T. Nagarajan, P. Sudhakar, R. Baskaran, Characterization of a novel natural cellulosic fiber from Prosopis juliflora bark, Carbohydr. Polym. 92 (2013) 1928-1933. https://doi.org/10.1016/j.carbpol.2012.11.064

[20]Y. Hu, O. Hamed, R. Salghi, N. Abidi, S. Jodeh, R. Hattb, Extraction and characterization of cellulose from agricultural waste argan press cake, Cellul. Chem. Technol. 51 (2017) 263-272. [21]W. Wang, R.C. Sabo, M.D. Mozuch, P. Kersten, J.Y. Zhu, Y. Jin, Physical and Mechanical Properties of Cellulose Nanofibril Films from Bleached Eucalyptus Pulp by Endoglucanase Treatment and Microfluidization, J. Polym. Environ. 23 (2015) 551-558. https://doi.org/10.1007/s10924-015-0726-7

[22] R. Liu, H. Yu, Y. Huang, Structure and morphology of cellulose in wheat straw, Cellulose 12 (2005) 25-34. https://doi.org/10.1023/b:cell.0000049346.28276.95 